\title{
Functional Modification of Borassus flabellifer Sheath Fibres Using Isocyanate
}

\author{
Ponnusamy Thillai Arasu 1,*(D), Panneer Selvam Seenidurai ${ }^{2}$ (D), Arumugam Murugan ${ }^{3 *(D)}$, \\ Sampandam Elangovan 4 (iD)
}

1 Department of Chemistry, Wollega University, Post Box No.395, Nekemte, Ethiopia; drpthillaiarasu@ gmail.com (P.T.A.);

2 Research and Development Centre, Bharathiar University, Coimbatore - 641046, Tamil Nadu, India; seenidurai@gmail.com (P.S.S.);

3 Department of Chemistry, North Eastern Regional Institute of Science \& Technology, Nirjuli, Itanagar-791109, Arunachal Pradesh, India; amu@ @erist.ac.in (A.M.);

4 Department of Physics, College of Natural and Computational Science, Wollega University, Nekemte, Ethiopia-395; elangovan.physics@ rediffmail.com (S.E.);

* Correspondence: drpthillaiarasu@gmail.com (P.T.A.); amu@ nerist.ac.in (A.M);

Scopus Author ID 57098234000 (P.T.A.) Scopus Author ID 57200496257 (A.M)

Received: 12.07.2020; Revised: 24.09.2020; Accepted: 29.09.2020; Published: 3.10.2020

Abstract: An active hydroxyl content of Borassus flabellifer leaf sheath fibers are measured by the isocyanate back titration method, catalytically reacted with 1, 6- hexamethylene diisocyanate biuret trimer and 2, 4-toluene diisocyanate-trimethylolpropane adduct, which is being used as cross-linkers in most of the automotive and industrial polyurethane coatings. The functional modifications of the fibers are confirmed by NCO titration method and Fourier-transform Infrared Spectroscopy (FTIR). The resultant biochemical fiber is analyzed for the thermal property, and surface topography measurement is done by Scanning Electron Microscope (SEM) and Thermogravimetric analysis (TGA), respectively. Moreover, 1, 6- hexamethylene diisocyanate biuret trimer (HDT) treated BFSF having higher thermal stability due to higher urethane to urea content and intermolecular hydrogen bonding.

Keywords: Borassus flabellifer leaf sheath; NCO titration method; FTIR study; SEM study; TGA study.

(C) 2020 by the authors. This article is an open-access article distributed under the terms and conditions of the Creative Commons Attribution (CC BY) license (https://creativecommons.org/licenses/by/4.0/).

\section{Introduction}

Owing to the presence of reactive - $\mathrm{OH}$ functional groups, light density, flexibility, high specific strength, textured surface topography of plant fibers have found -made tailor application in polymer and cement composites for soil erosion control, thermal insulation, and sound absorption architecture, oil spill cleanup, removal of reactive dyes, extraction of precious metals, textile, biomedical, microbial fuel cells, foldable supercapacitors, bio-based devices and conductive composites [1-9]. The major application of plant fibers is the prospective reinforcement in polymer composites. The plant fibers can be classified as bast (flax, kemp, kenaf, jute, nettle, and ramie), leaf (pineapple, sisal, abaca, tampico, and palm), seed (cotton, and kapok), fruit (coir, palm fruit, luffa) and reed (bamboo) fibers based on the source of extraction [10]. Though these fibers have several advantages, still they have some bottleneck because of the hydrophilic nature leads to poor fiber and polymer matrix interfacial adhesion and dimensional instability, inconsistent mechanical properties, susceptible to microbial attack, and low thermal stability [11]. The drawbacks can be overcome by suitable surface 
modifications detailed in the literature are (1) Chemical treatment: mercerization, acetylation, benzoylation, acrylation; acrylonitrile, maleic anhydride, silane, permanganate, peroxide, oleic acid, stearic acid, sodium -chloride, isocyanate, zein protein, and triazine treatments; (2) Physical treatment: corona, plasma, heat and surface fibrillation; (3) Biological treatment: microbial and enzymes [11-13].

Among all the vegetable -fibers, the fibers of the Asian palm tree Borassus flabellifer are significant because of their low density than any other natural and synthetic fibers [14], and it gives fibers from leaf sheath, stalk, and fruits. Studies on the thermal, mechanical, and morphological properties of alkali Borassus flabellifer fruit fiber and its polymer composites showed the increase in tensile strength, modulus, and percentage of elongation by 41, 69, and $40 \%$ respectively for $5 \%$ alkali treatment with a time span of $8 \mathrm{~h}$ because of the partial removal of more hydrophilic hemicellulose content [15-16]. It was investigated the mechanical properties of alkali-treated Borassus stalk fiber reinforced polyester composite and observed that the tensile and flexural strength improvement for alkali-treated Borassus stalk fiber reinforced polyester composites [17]. The organic chemical treatments of Borassus leaf sheath fiber have not yet been studied. Among various surface treatment persists, isocyanate treatment is privileged due to the competitive reaction between the $-\mathrm{OH}$ groups of cellulose, hemicellulose, and lignin constituents, moisture present in the fiber and NCO group to form covalent urethane and urea linkages between the fiber and matrix, the formed urea further reacts with the isocyanate groups to form a complex interpenetrating network and reduces the waterabsorbing tendency of natural fibers through barrier effect which enables the fiber - matrix wettability, acts as good load-bearing moieties between the fiber and most of the thermosetting matrices [13].

An isocyanate treatment involves the reaction between the NCO group and the hydroxyl group present in the macromolecular polyol, cellulose. It had been studied that the pulp was modified with n-butylisocyanate, 1, 6-hexamethylene diisocyanate, phenyl isocyanate, diphenymethane diisocyanate (MDI) respectively and found to the reduction in moisture intake and increased thermal property [18]. The low molecular mass monomeric isocyanates are having high vapor pressure and are potentially hazardous to humans. Therefore, the relatively high molecular weight, low vapor pressure, and less toxic HDT and 2, 4- toluene diisocyanate - trimethylolpropane adduct (TPA), are predominant curing agent for polyester, acrylic, polyether, and polycarbonate polyols in the coating, adhesive, elastomer, and insulation industry [19], are used for surface modification of Borassus flabellifer leaf sheath fiber and its chemical bonding nature, surface morphology and thermal characterization are examined in this study.

\section{Materials and Methods}

\subsection{Materials.}

The raw fiber extracted from the palm tree Borassus flabellifer leaf sheath (BFSF) and Desmodur N75 (HDT), Desmodur L75 (TPA), Dibutyltin dilaurate (DBTDL), butyl acetate were purchased from Vimal Intertrade Chennai, were used as such for this study.

\subsection{Determination of the number of reactive hydroxyl groups.}

The number of a reactive hydroxyl group of BFSF fiber were determined by the isocyanate group back titration (IBT) method described in the literature [20], and five random 
samples analyzed; the results were averaged, expressed in terms of hydroxyl number $(\mathrm{OH \#}$, $\mathrm{mgKOH} / \mathrm{g}$ ) and converted into $\% \mathrm{OH}$ content by the following relation.

$$
\% \mathrm{OH} \text { content }=\frac{\mathrm{OH} \#}{33.33}
$$

\subsection{Isocyanate treatment.}

The quantity of isocyanate required for the surface modification of BFSF, while maintaining the stoichiometry of $\mathrm{OH} / \mathrm{NCO}=1$ can be calculated by the following expression.

$$
\text { Quantity of NCO required }(\mathrm{g})=\frac{\boldsymbol{W} \times \% \boldsymbol{O H} \times 42}{\% \boldsymbol{N C O} \times 17}
$$

Where $\mathrm{W}$ is the quantity of fiber is to be treated; $\% \mathrm{OH}$ is the reactive hydroxyl content of the BFSF, which was calculated from IBT method, \% NCO is the isocyanate content of HDT and TPA given by the supplier, the value 17 and 42 are the molecular weight of hydroxyl and isocyanate group respectively. Pre-weighed, shortly cut BFSF were taken in an athree-necked flask in butyl acetate solvent medium, and the required quantity of isocyanate was added to the flask under stirring and continuous nitrogen flow at room temperature. 1\% DBTDL solution based on isocyanate resin solid was added to the flask under stirring, and the temperature of the reaction mixture was raised, maintained between $70-75^{\circ} \mathrm{C}$ for $1-2 \mathrm{hr}$ till all the NCO groups are consumed, which was confirmed by NCO titration method. Then, the reaction mass allowed to cool to room temperature and filtered, washed, the fibers are dried at $50^{\circ} \mathrm{C}$ for 4 hours.

\subsection{TGA study.}

Thermogravimetric analysis of the fiber samples was performed using the TA Q600 Instrument equipped with an autosampler, and three replications were performed. The thermograms were recorded between $20^{\circ} \mathrm{C}$ and $800^{\circ} \mathrm{C}$ with a heating rate of $10^{\circ} \mathrm{C} / \mathrm{min}$ in a flow of nitrogen at $100 \mathrm{ml} / \mathrm{min}$. The TGA curves were obtained directly from the apparatus, while the DTG curves were obtained by software TA advantage 5008 .

\subsection{SEM study.}

The microstructure and morphology of the BFSF were visualized using a scanning electron microscope (Zeiss) with an accelerated voltage of $20 \mathrm{kV}$ and an attainable vacuum level of $1.5 \times 10^{-3} \mathrm{~Pa}$.

\section{Results and Discussion}

\subsection{Reactive hydroxyl groups.}

The reactive hydroxyl number and $\% \mathrm{OH}$ of BFSF fiber were determined by the isocyanate group back titration (IBT) method as $251 \mathrm{mg} \mathrm{KOH} / \mathrm{g}$ and $7.53 \%$, which was higher than ramie fiber [20].

\subsection{FTIR study and titration.}

The reaction rates for HDT and TPA with BFSF is calculated through titrating of the free-NCO content of the reaction mixture at different interval until the mixture free from isocyanate group. The FTIR spectrum (Fig.1) supports the absence of free-NCO groups in HDT 
and TPA treated BFSF -fibers. The formation of urethane bonds are easily identified by the presence of a peak at $1681 \mathrm{~cm}^{-1}$ for HDT treated fibers and $1705 \mathrm{~cm}^{-1}$ for TPA treated fibers [21]. The presence of urea bond due to the moisture present in the BFSF is also confirmed by the peak at $1254 \mathrm{~cm}^{-1}$, and $1267 \mathrm{~cm}^{-1}$ for HDT and TPA treated BFSF, respectively. The intensity of urea is more in TPA-treated fibers due to the high reactivity of aromatic isocyanate towards water than aliphatic isocyanate, whereas the intensity of the urethane bond is more for HDT treated -fibers.

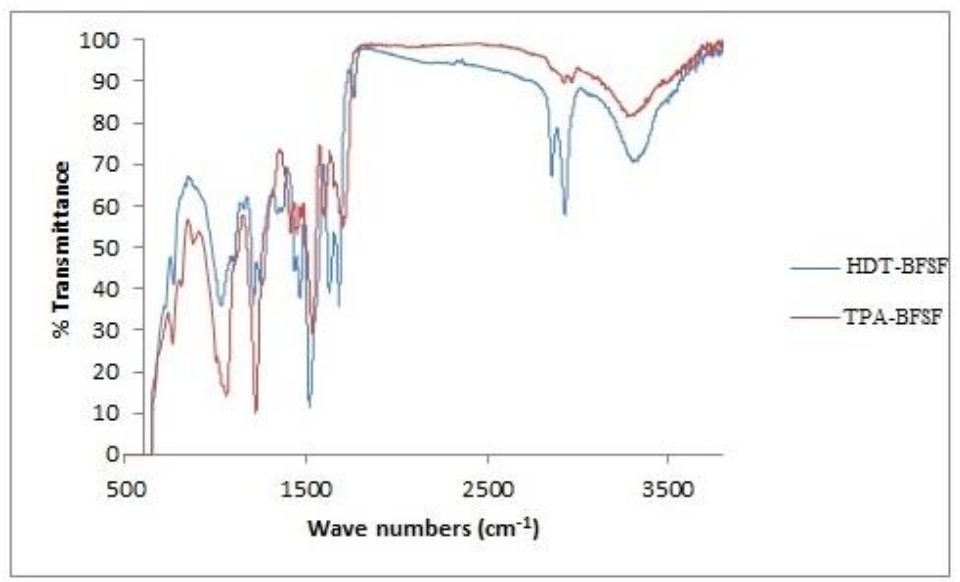

Figure 1. FTIR spectra of HDT, TPA treated Borassus flabellifer sheath fibers.

\subsection{TGA study.}

The first derivative thermogram (DTG) of HDT treated and TPA treated fibers are illustrated in Figure $2 a \& 2 b$, clearly reveals the inflection points. The first crest located at 55$60^{\circ} \mathrm{C}$ attributed to the moisture release, the second peak at $239^{\circ} \mathrm{C}$, and $248^{\circ} \mathrm{C}$ pertained to the disintegration of cellulose and hemicellulose of HDT-BFSF and TPA-BFSF. The disintegration peak at $172^{\circ} \mathrm{C}$ of TPA-BFSF is due to the low extent of hydrogen bonding [23], which is also confirmed from IR spectra (Fig.1). The peak temperatures (Tp) of HDT-BFSF and TPA-BFSF are $335^{\circ} \mathrm{C}$, and $331^{\circ} \mathrm{C}$ corresponds to the degradation of lignin polymers [24], and the peak temperature is higher than bagasse (299), bamboo (286), cotton stalk (293), hemp (282), jute (283), kenaf (284), rice husk (297), rice straw (273) and wood pine [22] (308). The results of the thermogravimetric analysis of BFSF are shown in Fig. 2a \& 2b. The TGA curve of HDT-BFSF and TPA-BFSF shows an initial weight loss of about $7.8 \%$ between 40 and $100^{\circ} \mathrm{C}$, which is attributed to the evaporation of bounded water molecules. In the second stage, modest horizontal curves were noted between $100^{\circ} \mathrm{C}$ and $200^{\circ} \mathrm{C}$ showed marginal mass loss of HDT-BFSF (2.12\%), and TPA-BFSF (3.14\%) is owing to the initiation of lignin degradation. In the third stage, the steep curve started from $200^{\circ} \mathrm{C}$ to $310^{\circ} \mathrm{C}$ is due to the thermal degradation of hemicellulose, and this stage there are found the mass loss of 29.59 and $25.06 \%$ corresponds to the HDT-BFSF and TPA-BFSF, respectively. HDT-BFSF is an aliphatic polymer which undergone decomposition rapidly than TPA-BFSF. The fourth stage curve between 310 and $360^{\circ} \mathrm{C}$ was attributed degradation of the cellulosic polymer, and the mass loss of 19.78 and $12.55 \%$ corresponds to the HDT-BFSF and TPA-BFSF, respectively. Fifth ease In Cubic lines from 360 to $790^{\circ}$ is affected by the degradation of lignin polymer and the molecule breakdown into a variety of low molecular weight products. The thermal decomposition of TPA-BFSF is found to higher than HDT-BFSF due to the presence of the aromatic group in TPA-BFSF. TGA shows that the presence of HDT-BFSF and TPA-BFSF having a moisture content of about $8 \%$, 
whereas the raw BFSF having moisture content $13 \%$ and about $5 \%$ of the moisture is reduced due to the reaction with isocyanate.

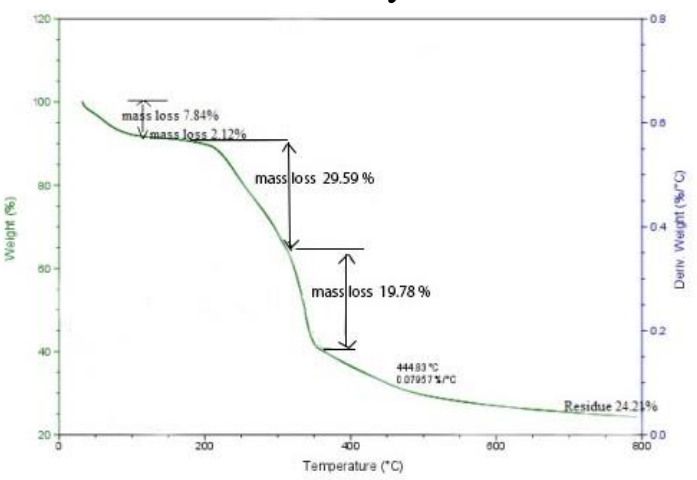

(a)

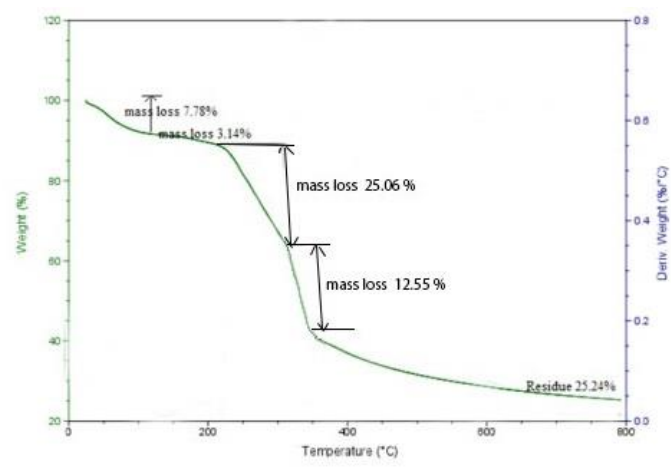

(b)

Figure 2. TGA curve of (a) HDT treated Borassus flabellifer sheath fibers and (b) TPA treated Borassus flabellifer sheath fibers.

\subsection{Surface morphology.}

The formations of the chemical bond between HDT, TPA, and BFSF have also been confirmed by SEM - EDX images. The chemical bond formed uniformly on the surface of the BFSF treated by HDT (Fig.3A) is due to the symmetric structure of HDT, whereas TPA-BFSF (Fig.3B) showed discontinuity because of the difference in reactivity of isocyanate groups present in the toluene diisocyanate adduct. The isocyanate group located in TPA adjacent to the methyl group is less reactive than the para isocyanate due to the steric effect. The rough, pitted surface of raw BFSF (Fig.3C) is covered by the polymeric layer after isocyanate treatment (Fig.3D).

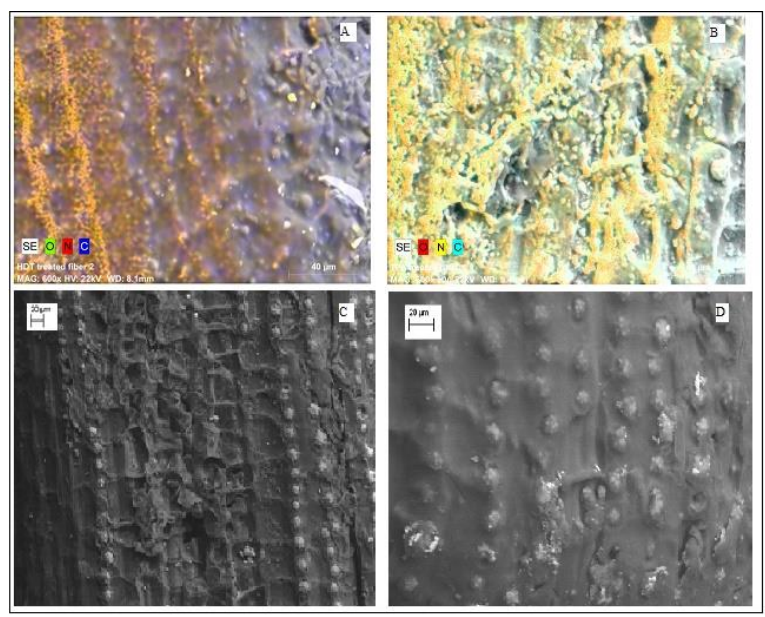

Figure 3. SEM-EDX image of HDT-BFSF (A) TPA-BFSF, (B) raw BFSF (C) and isocyanate treated BFSF (D).

\section{Conclusions}

The HDT-BFSF and TPA-BFSF characterization results clearly indicate the fibers are free from the isocyanate group, and each polysaccharide chain is linked together by an interpenetrated network of urethane and urea bonds, high thermal stability from which may be considered as an engineering fiber. However, HDT-BFSF having high thermal stability due to higher urethane to urea content and intermolecular hydrogen bonding. SEM-EDX images confirmed the presence of a polymeric layer encapsulated on the BFSF fiber. These fibers could 
be used as a reinforcement for polymeric composite and isocyanate spill kit due to the presence of high functionality and moisture content.

\section{Funding}

This research received no external funding.

\section{Acknowledgments}

The authors would like to thank Mr. S. M. Suresh Kumar, Anna University, Chennai 600 025, India, for his excellent support for doing this research work.

\section{Conflicts of Interest}

The authors declare no conflict of interest.

\section{References}

1. Ge, D.; Yang, L.; Fan, L.; Zhang, C.; Xiao, X.; Gogotsi Y.; Yang, S. Foldable supercapacitors from triple networks of macroporous cellulose fibers, single-walled carbon nanotubes and polyaniline nanoribbons. Nano Energy 2015, 11, 568-578, https://doi.org/10.1016/j.nanoen.2014.11.023.

2. Mittal, A.; Garg, S.; Bajpai, S. Thermal decomposition kinetics and properties of grafted barley husk reinforced PVC/starch composite films for packaging applications. Carbohy. Poly. 2020, 240, 116225116347, https://doi.org/10.1016/j.carbpol.2020.116225.

3. Kulma, A.; Skórkowska-Telichowska, K.; Kostyn, K.; Szatkowski, M.; Skała, J.; Drulis-Kawa, Z.; Preisner, M.; Zuk, M.; Szperlik, J.; Wang, Y.F.; Szopa, J. New flax producing bioplastic fibers for medical purposes. Ind. Crop. Prod. 2015, 68, 80-89, https://doi.org/10.1016/j.indcrop.2014.09.013.

4. Kalia, S.; Thakur, K.; Celli, A.; Kiechel, M.A.; Schauer, C.L. Surface modification of plant fibers using environment friendly methods for their application in polymer composites, textile industry and antimicrobial activities: a review. J. Env. Che. Eng. 2013, 1, 97-112, https://doi.org/10.1016/j.jece.2013.04.009.

5. Hassan, M.S. Removal of reactive dyes from textile wastewater by immobilized chitosan upon grafted jute fibers with acrylic acid by gamma irradiation. Radiat. Phys. Chem. 2015, 115, 55-61, https://doi.org/10.1016/j.radphyschem.2015.05.038.

6. Merlini, C.; Barra, G.M.O.; Schmitz, D.P.; Ramôa, S.D.A.S.; Silveira, A.; Araujo, T.M.; Pegoretti, A. Polyaniline-coated coconut fibers: Structure, properties and their use as conductive additives in matrix of polyurethane derived from castor oil. Polym. Test. 2014, 38, 18-25, https://doi.org/10.1016/j.polymertesting.2014.06.005.

7. Dong, T.; Xu, G.; Wang, F. Oil spill cleanup by structured natural sorbents made from cattail fibers. Ind. Crop. Prod, 2015, 76, 25-33, https://doi.org/10.1016/j.indcrop.2015.06.034.

8. Zhang, C.; Jiang, Y.X.; Sun, J.P,; Xiao, H,; Shi, M.W,; Long, J.J. Investigation of the influence of supercritical carbon dioxide treatment on meta-aramid fiber: Thermal decomposition behavior and kinetics. J. CO2 Utiliz. 2020, 37, 85-96, https://doi.org/10.1016/j.jcou.2019.10.007.

9. Sharma, V.; Vinayak, H.K.; Marwaha, B.M. Enhancing compressive strength of soil using natural fibers. Constr. Build. Mater. 2015, 93, 943-949, https://doi.org/10.1016/j.conbuildmat.2015.05.065.

10. Kicinska - Jakubowska, A.; Bogacz, E.; Zimniewska, M. Review of natural fibers. Part I-Vegetable fibers. J. Nat. Fibres 2012, 9, 150-167, https://doi.org/10.1080/15440478.2012.703370.

11. El-Sabbagh, A. Effect of coupling agent on natural fibers/polypropylene composites on mechanical and thermal behavior. Compos. Part B: Engin. 2014, 57, 126-135, https://doi.org/10.1016/j.compositesb.2013.09.047.

12. Bugarin, S.; Paskaramoorthy, R; Reid R.G. Influence of the geometry and material properties on the dynamic stress field in the matrix containing a spheroidal particle reinforcement. Compos. Part B: Engin. 2012, 43, 272-279, https://doi.org/10.1016/j.compositesb.2011.06.005.

13. Kabir, M.M.; Wang, H.; Lau, K.T.; Cardona, F. Chemical treatments on plant-based natural fibre reinforced polymer composites: An overview. Compos. Part B: Engin. 2012, 43, 2883-2892, http://dx.doi.org/10.1016/j.compositesb.2012.04.053.

14. Indran, S.; Raj, R.E. Characterization of new natural cellulosic fiber from Cissus quadrangularis stem. Carbohyd. Polym. 2015, 117, 392-399, https://doi.org/10.1016/j.carbpol.2014.09.072.

15. Reddy, K.O.; Maheswari, C.U.; Shukla, M.; Song, J.I.; Rajulu, A.V. Tensile and structural characterization of alkali treated Borassus fruit fine fibers. Compos. Part B: Engin. 2013, 44, 433-438, https://doi.org/10.1016/j.compositesb.2012.04.075. 
16. Boopathi, L.; Sampath, P.S.; Mylsamy, K. Investigation of physical, chemical and mechanical properties of raw and alkali treated Borassus fruit fibers. Compos. Part B: Engin. 2012, 43, 3044-3052, https://doi.org/10.1016/j.compositesb.2012.05.002.

17. Shanmugam, D.; Thiruchitrambalam, M. Static and dynamic mechanical properties of alkali treated unidirectional continuous palmyra palm leaf stalk fiber/jute fiber reinforced hybrid polyester composites. Materials Design 2013, 50, 533- 542, https://doi.org/10.1016/j.matdes.2013.03.048.

18. Piglowska, M,; Kurc, B.; Rymaniak, L,; Lijewski, P,; Fuc, P. Kinetics and Thermodynamics of thermal degradation of different starches and estimation the $\mathrm{OH}$ group and $\mathrm{H}_{2} \mathrm{O}$ content on the surface by TG/DTGDTA. Polymers, 2020, 12, 357, 7, https://doi.org/10.3390/polym12020357

19. Kapp, J.R.W. Isocyanates (Module in Biomedical Science). In: Encyclopedia of Toxicology. $3^{\text {rd }}$ ed.; Philip Wexler., eds.; Academic Press, 2014; pp. 1112.

20. He, L.; Li, X.; Li, W.; Yuan, W.J.; Zhou, H. A method for determining reactive hydroxyl groups in natural fibers: application to ramie fiber and its modification. Carbohydr Res. 2012, 348, 95-98, https://doi.org/10.1016/j.carres.2011.10.035.

21. Huda, M.S.; Drzal, L.T.; Misra, M.; Mohanty, A.K.; Williams, K.; Mielewski, D.F. A study on biocomposites from recycled newspaper fiber and polylactic acid. Ind. Eng. Chem. Res. 2005, 44, 55935601, https://doi.org/10.1021/ie0488849.

22. Laouge, Z.B.; Merdun, H.; Pyrolysis and combustion kinetics of Sida cordifoia L, using thermogravimetric analysis. Biores. Tech. 2020, 299, 122602-122610, https://doi.org/10.1016/j.biortech.2019.122602.

23. Ranjbar, Z.; Montazeri, S.; Nayini, M.M.R.; Jannaseri, A. Synthesis and characterization of diethylene glycol monobuty ether - Blocked diisocyanate cross-linkers. Prog. Org. Coat. 2010, 69, 426-431, https://doi.org/10.1016/j.porgcoat.2010.08.009.

24. Yuezhen, M.; Xintong, W.; Mengshu, X.; Kezhen, Q.; Zengze, C.; Qiuju, S. Thermal decomposition dynamics of nylon 66 nad its composities. Chinese J. Mat. Res. 2020, 34, 599604, https://doi.org/10.11901/1005.3093.2019.570. 